\title{
Guest Editorial: Special Issue on XXIII Brazilian Congress of Automatics (CBA 2020)
}

\author{
Tiago Roux Oliveira ${ }^{1}$. Daniel Pinheiro Bernardon ${ }^{2} \cdot$ José Paulo V. S. Cunha $^{1}$
}

Received: 3 November 2021 / Accepted: 3 November 2021 / Published online: 18 November 2021

(c) Brazilian Society for Automatics--SBA 2021

This special issue is the first devoted to invited papers presented at the Brazilian Congress of Automatics (XXIII Congresso Brasileiro de Automática CBA 2020). This has been the main conference sponsored biannually by the Brazilian Society of Automatics (Sociedade Brasileira de Automática SBA) since 1976, as is presented in the historic review "Celebrating 45 Years of the Brazilian Society of Automatics" the first paper of this special issue.

CBA 2020 was scheduled to take place on November 23-26, 2020, in Porto Alegre (Rio Grande do Sul, Brazil). However, the outbreak of the COVID-19 pandemic imposed the challenging organization of the first virtual CBA, which has been a model for subsequent events sponsored by SBA. As in previous editions, the congress had attracted the attention of the authors, with 1034 submissions and 777 accepted papers. The authors of selected papers had been invited to submit extended and improved versions of their manuscripts to this special issue. After a regular peer review process, twenty-nine of these had been included. We would like to apologize that many excellent invited papers had not been ready in due time to be included in this special issue. These papers will be published in forthcoming regular issues.

The areas of the papers published in this issue include control theory, robotics, intelligent systems, power systems and electric machines. This illustrates the broad scope of the SBA, CBA and the Journal of Control, Automation and Electrical Systems.

Tiago Roux Oliveira

tiagoroux@uerj.br

Daniel Pinheiro Bernardon

dpbernardon@ufsm.br

José Paulo V. S. Cunha

jpaulo@uerj.br

1 State University of Rio de Janeiro (UERJ), Rio de Janeiro, Brazil

2 Federal University of Santa Maria (UFSM), Santa Maria, Brazil
Dedicated to the memory of millions who died in consequence of the COVID-19 disease, in these difficult pandemic days that changed life and will be part of the memories of billions of human beings, we must highlight that all the papers presented at the Special Session on "Modeling and Control of Dynamic Systems in the COVID-19 Pandemic" had been invited to this special issue. Five of these have been included here. We must remind the readers that these papers present concepts that seemed reasonable in the beginning of the pandemic, when reinfections had not yet been verified and no vaccine for the SARS-CoV-2 was available. These and others yet to be discovered have been changing the dynamic behavior of the COVID-19 pandemic, which is unfortunately still going on. We hope that researchers in the fields of control and dynamic systems become interested in this subject, such that more efficient control strategies and dynamic models can be developed in due time to support government decisions based on solid scientific and technical foundations in order to avoid new pandemics.

Acknowledgements The guest editors would like to express sincere thanks to all the authors for their contributions to the congress and to this Special Issue and the reviewers for their comments which improved the quality of the manuscripts. We must also recognize the great support by the Editor-in-Chief of JCAES, Prof. Antonio Padilha Feltrin, the Past President of the Brazilian Society of Automatics, Prof. Vilma A. Oliveira, and the Springer Journal Development Editor (Engineering), Mr. Brock Madsen, for supporting the publication of this special issue.

Publisher's Note Springer Nature remains neutral with regard to jurisdictional claims in published maps and institutional affiliations. 